\title{
Form-specific visual priming for new associations in the right cerebral hemisphere
}

\author{
CHAD J. MARSOLEK \\ University of Arizona, Tucson, Arizona \\ DANIEL L. SCHACTER \\ Harvard University, Cambridge, Massachusetts \\ and \\ CHRISTOPHER D. NICHOLAS \\ University of Arizona, Tucson, Arizona
}

\begin{abstract}
In three experiments, we examined the internal processing mechanisms of relatively independent visual-form subsystems. Participants first viewed centrally presented word pairs and then completed word stems presented beneath context words in the left or right visual field. Letter-case-specific priming in stem completion was found only when the context word was the same word that had previously appeared above the primed completion word and the items were presented directly to the right cerebral hemisphere. This pattern of results was not found when participants deliberately recollected previously presented words when completing the stems. Results suggest that holistic processing, not parts-based processing as assumed in many contemporary theories of visual-form recognition, is performed in a subsystem that distinguishes specific instances in the same abstract category of form and that operates more effectively in the right hemisphere than in the left hemisphere.
\end{abstract}

The ability to distinguish specific instances in the same abstract category of visual form is an important human faculty. One can differentiate a particular cup from other cups as well as an individual's signature from other written versions of the same set of letters. An interesting aspect of this ability is that most theories of visual-form recognition, aside from theories that address only face recognition (e.g., Bruce \& Young, 1986; Rhodes, 1985), do not focus on how it is accomplished. Most theories focus instead on the ability to distinguish different abstract types of visual forms (e.g., Biederman, 1987; Morton, 1979). Of course, the latter ability is also important and interesting. One can distinguish a cup from a pen, as well as the word form "cup" from the word form "pen," even when the input is an instance that has not been seen before. In the research reported in this article, we tested whether at least relatively independent processing subsystems support the two abilities. More importantly, we

\footnotetext{
This research was supported by a Jacob K. Javits Graduate Fellowship and NIMH Grant MH53959-01, awarded to C.J.M., and by NIMH Grant MH45398-01A3, awarded to D.L.S. The work was also supported by the McDonnell-Pew Cognitive Neuroscience Center and the Arizona Cognitive Science Program at the University of Arizona. We wish to thank Chris Azorson for substantial discussion and Larry Beer and Ann Pudori for help with data collection and analysis. We also thank Darcy Burgund and Joe Cruz for comments on earlier drafts of this manuseript. Correspondence should be addressed to C. J. Marsolek, Department of Psychology, University of Minnesota, Minneapolis, MN 55455 (e-mail: marso002@gold.tc.umn.edu).
}

examined form-specific priming for novel holistic structures to test whether holistic processing, as opposed to parts-based processing of the sort assumed in many contemporary theories of visual form recognition (e.g., Biederman, 1987; Morton, 1979), characterizes the operations in a subsystem that distinguishes specific instances in an abstract category of form.

\section{VISUAL-FORM SUBSYSTEMS}

We hypothesize that a specific visual-form (SVF) subsystem underlies recognition of specific instances of forms and operates more effectively in the right cerebral hemisphere $(\mathrm{RH})$ than in the left cerebral hemisphere (LH). In contrast, an abstract visual-form (AVF) subsystem supports recognition of abstract categories of forms and operates more effectively in the LH than in the RH. These subsystems likely focus on different properties of visual-form inputs to achieve different goals.

\section{SVF Subsystem}

In order to produce different outputs when different instances in the same abstract category appear as inputs, an SVF subsystem must process a form's visually distinctive information effectively. Visually distinctive information refers to the specific structural properties that vary across the different instances in an abstract category. For example, the lowercase form " $p$ " and the uppercase form "P" have structurally distinct vertices at both connecting points between the vertical line and the enclosed space, 
as well as structurally distinct shapes to the enclosed spaces. All of this information may be needed to distinguish specific instances of that letter.

Recent evidence indicates that visually distinctive information is stored in a subsystem that operates more effectively in the RH than in the LH. In word-stem completion experiments (Marsolek, Kosslyn, \& Squire, 1992; Marsolek, Squire, Kosslyn, \& Lulenski, 1994), greater repetition priming has been obtained when initially presented prime words and subsequently presented word stems appeared in the same letter case than in different letter cases. More importantly, this letter-case-specific priming effect has been found to be greater when stems were presented directly to the RH (in the left visual field) than when stems were presented directly to the LH (in the right visual field).

\section{AVF Subsystem}

In order to produce the same output when different instances in the same abstract category are accepted as input, an AVF subsystem must process visual features that are relatively invariant across the different instances. These relatively invariant features may include the nonaccidental properties of the edges of structures, such as instances of connectivity, collinearity, parallelism, and other properties (Lowe, 1985, 1987). For example, regardless of the font or typestyle in which the form is printed, both " $p$ " and " $P$ " contain a vertical line and an enclosed space that exhibit some kind of connectivity near the top of the vertical line and at a point roughly halfway down the vertical line. This is the kind of information that is needed to recognize abstract categories of forms effectively. 1

Further evidence indicates that relatively invariant features are stored in a subsystem that operates more effectively in the LH than in the RH. In visual classification experiments (Marsolek, 1995), previously unseen prototypes of newly learned types of forms, but not previously seen nor previously unseen distortions of the prototypes, were categorized more effectively when the forms were presented directly to the LH than to the RH. A subsystem that stores relatively invariant features effectively should process prototypes effectively, because they contain the features that are common to the different instances within an abstract category but not the information that distinguishes the different instances.

Taken together, these findings indicate that two visualform subsystems operate relatively independently in the brain. In divided-visual-field tasks, the visual information presented directly to one hemisphere must cross brain commissures to be processed by the other hemisphere. As a result, subsystems in the first hemisphere obtain higher quality information and obtain it more quickly than do subsystems in the other hemisphere. Because SVF processing is performed more effectively when higher quality visual input is processed initially in the $\mathrm{RH}$ than in the $\mathrm{LH}$, whereas AVF processing is performed more effectively when higher quality visual input is processed initially in the LH than in the RH, an SVF sub- system and an AVF subsystem must operate in at least a weakly modular manner. ${ }^{2}$

These subsystems are hypothesized to store visual structure information about word and object forms, but not semantic or conceptual information associated with them. Hence, they appear to operate as subsystems of the perceptual representation system (Schacter, 1990, 1992, 1994; Tulving \& Schacter, 1990). This system stores modality-specific information that normally supports perceptual repetition priming effects like those described above. This system is composed of visual and auditory subsystems and perhaps more. Schacter (1994) pointed out that it is not clear yet whether the visual subsystems should be delineated into LH and RH (AVF vs. SVF) subsystems or whether they should be parceled into visual word-form and structural-description systems that each are composed of LH and RH (AVF vs. SVF) subsystems. We leave this question open for now. Our theory and findings are discussed in terms of AVF and SVF subsystems that should be understood as components of the perceptual representation system.

\section{INTERNAL PROCESSING MECHANISMS}

In the following series of experiments, we further test whether these two visual-form subsystems operate relatively independently, and we investigate the structures and processes utilized by these subsystems. Important clues about these properties can come from analyses of the kinds of inputs they accept and from examinations of the goals for the outputs they produce (Marr, 1982). Such analyses lead to the hypothesis that holistic processing characterizes an SVF subsystem, whereas partsbased processing characterizes an AVF subsystem.

\section{Holistic Processing in an SVF Subsystem}

An analysis of the goals for an SVF subsystem suggests that holistic processing may characterize its computations. In this article, "holistic" processing means that parts are not explicitly represented as such at any stage of processing and information about perhaps an entire input form is represented at all stages of processing. Usually, the information that distinguishes a specific instance is the holistic structure of the form, including potentially all of the information in the entire form. For example, information about the whole of the form " $p$ " is needed to distinguish it from " $P$ " or a visually similar letter like "b." Thus, holistic processing may characterize an SVF subsystem.

In addition, an analysis of the information available in the input to visual-form subsystems also suggests that holistic processing may characterize an SVF subsystem. Primary visual cortex represents inputs in a retinotopically mapped format (Fox, Miezen, Allman, Van Essen, \& Raichle, 1987; Kosslyn et al., 1993; Tootell, Silverman, Switkes, \& De Valois, 1982). Information is coded pictorially, as a pattern of points distributed across a functional space in two dimensions. By their nature, pictorial representations can store the information that distin- 
guishes specific instances of forms as specific patterns of points across the functional space. For example, the pattern " $p$ " on this paper is a pictorial representation that is different from the pattern "P." The two representations distinguish two instances in the same abstract category of form. An SVF subsystem may take advantage of pictorially coded inputs and perform a process akin to pictorial interpolation or pictorial alignment (e.g., Bülthoff \& Edelman, 1992; Huttenlocher \& Ullman, 1990; Lowe, 1987; Tarr, 1995; Ullman \& Basri, 1991). In this approach to form recognition, a holistic comparison process is used to compare pictorially coded inputs and representations in storage. An interpolation or alignment procedure is applied during the comparison process, allowing the subsystem to recognize shapes that appear in retinal locations, orientations, and sizes that have not been seen before, hence greatly reducing the potential number of representations that the subsystem must store to recognize a shape.

\section{Parts-Based Processing in an AVF Subsystem}

In contrast, an analysis of the goals for an AVF subsystem suggests that parts-based processing may characterize its computations. An AVF subsystem should store relatively invariant features effectively, and most of such features are parts of forms. Therefore, this subsystem should represent parts explicitly as parts. For example, a parts-based representation of the letter " $p$ " may indicate that one part (an enclosed space) is upper-left-connected to another part (a vertical line). Such a representation is general enough to represent both a lowercase " $p$ " and an uppercase "P."

Consistent with this analysis, an AVF subsystem may perform a structural-description process (e.g., Biederman, 1987; Hummel \& Biederman, 1992; Marr \& Nishihara, 1978; Palmer, 1975; Schacter, Cooper, \& Delaney, 1990; Sutherland, 1968; Winston, 1975). This is a partsbased approach to form recognition, in which information is coded propositionally, as a list of symbols representing parts and spatial relations among them. The parts of an input form necessarily are represented as such before propositional representations of inputs are compared against propositional representations in storage. ${ }^{3}$

\section{PRIMING FOR NOVEL VISUAL-FORM INFORMATION}

The following experiments test the foregoing hypotheses in a way that may help to illuminate critical aspects of how unfamiliar visual forms are learned. We examine SVF priming for new visual-form information. Critically, we assume that the unique aspect of any novel visual form is its holistic structure. At least for adults, most novel forms contain parts that are familiar and/or shared with well-known forms (cf. Biederman, 1987; Biederman \& Cooper, 1991). Moreover, most forms exhibit edges that contain nonaccidental properties (Lowe, 1985, 1987), whether the forms are novel or not. Thus, the nonaccidental properties of a novel form could be processed in the same way as the nonaccidental properties of a familiar form. For these reasons, representations of the holistic structures of unfamiliar forms, but not representations of their parts per se, should support priming for the novel aspects of unfamiliar forms.

Both parts-based and holistic processing subsystems could store the information about holistic structure that supports priming for novel information, but in different ways and to different degrees by proportion. In a partsbased subsystem, structural changes in the final stage of processing, a stage in which the whole of a form is represented in terms of how parts are spatially related to each other to form the whole, could support priming for novel information. It is important to note, however, that structural changes in a prior stage of processing, a stage in which the parts are represented as such but the holistic structure is not represented yet, should support priming for nonnovel information in the form. In contrast, all of the priming in a holistic subsystem should be supported by structural changes in a mechanism that always represents holistic structure, as there are no stages of processing in which holistic structure is not represented.

This reasoning leads to an interesting prediction. At least some of the priming in a parts-based subsystem should not be influenced by representations of holistic structure, whereas all of the priming in a holistic subsystem should be based on representations of holistic structure. Given that the novel aspects of an unfamiliar form reside in its holistic structure, a holistic subsystem should support priming for those novel aspects to a greater degree by proportion ( $100 \%$ of its priming is for holistic information) than a parts-based subsystem $(<100 \%$ of its priming is for holistic information). We can assume that an SVF subsystem supports an overall level of priming that is at least close to the overall level supported by an AVF subsystem (see results in Marsolek et al., 1992). Thus, if holistic processing characterizes an SVF subsystem whereas parts-based processing characterizes an AVF subsystem, an SVF subsystem should support greater priming for novel information (e.g., new holisticstructure information) than an AVF subsystem.

We have tested this reasoning through examinations of priming for new visual associations between unrelated words (e.g., Graf \& Schacter, 1985, 1987, 1989; Schacter \& Graf, 1986a, 1986b, 1989). We have used the wordstem completion task for several reasons. First, we wish to examine priming for novel holistic information using a task that is very similar to that used in previous studies indicating that an SVF subsystem operates more effectively in the RH than in the LH (word-stem completion; Marsolek et al., 1992, 1994). Second, other word priming tasks tend to be problematic for the purpose of investigating hemispheric asymmetries for SVF priming: word fragments cannot be viewed with a high degree of accuracy when presented briefly in the visual periphery, and completing them tends to promote time-consuming search strategies that need not involve processing of visual information per se; lexical decisions are binary decisions that potentially can be made without accessing a 
representation of each entire target word, unlike when particular word responses are produced (this may be especially important for examining SVF priming that appears to be supported by holistic representations); and perceptual identification tends to produce asymmetries in baseline performance (Burgund \& Marsolek, 1996; Koivisto, 1995, in press) and usually requires backward pattern masking, which very likely interferes with normal patterns of SVF priming (see Marsolek et al., 1992; cf. Schacter \& Church, 1992, in the auditory domain). Third, word-stem completion may be a relatively conservative task for our purpose. During test, the target item (a word stem) is always a visual form that differs from the prime item (a complete word). Thus, the SVF priming we have obtained is found under a condition that to some extent works against finding any such effects at all. Yet, we have consistently found significant results (see also Marsolek et al., 1992, 1994).

\section{EXPERIMENT 1A}

During the initial encoding phase of this experiment, participants viewed a list of word pairs, one word printed above the other in each pair, and determined whether the number of vowels in each word of a pair was the same or different. Both words in each pair were presented in all lowercase or in all uppercase letters. During the subsequent test phase of the experiment, participants viewed three-letter word stems presented beneath complete context words and completed each stem to form the first word that came to mind. Both items in each trial appeared briefly in either the left or the right visual field and in either all lowercase or all uppercase letters. In half of the test trials, the stems could have been completed to form words that were previously presented (old trials), and in the other half of the trials, the stems could not have been completed to form words that were previously presented (new trials). In half of the old trials, the stems could have been completed to form words that had appeared previously beneath the same context word that was presented above the stem. In the other half of the old trials, the stems could have been completed to form words that had appeared previously beneath a different context word from the one that was presented above the stem. Furthermore, half of the same-context trials and half of the different-context trials included stems that appeared in the same letter case as that in which their corresponding words had been presented earlier, and the other halves included stems that appeared in the different letter case from that in which their corresponding words were presented. Repetition priming was measured as the greater-than-chance tendency to complete stems using previously processed words.

In this experiment, priming for novel holistic structures could be obtained in the same-context condition, but not in the different-context condition. This is important because all of the priming supported by a holistic processing subsystem, but only some of the priming supported by a parts-based processing subsystem, should be based on representations of holistic structure. Thus, if holistic processing characterizes an SVF subsystem whereas partsbased processing characterizes an AVF subsystem, we should observe an interaction between context, case, and hemisphere. We should find greater letter-case-specific priming (i.e., greater same-case priming than differentcase priming) in $\mathrm{RH}$ than in LH test presentations (as in previous single-word priming experiments; Marsolek et al., 1992, 1994), but only in the same-context condition in which priming for holistic structures can be obtained, and not in the different-context condition, in which priming for holistic structures cannot be obtained. Such a finding would indicate that the same subsystem that supports letter-case-specific priming also performs holistic processing to support priming for novel visual wholes.

\section{Method}

\section{Participants}

Thirty-two male Harvard University students volunteered as paid participants. All were native English speakers, and all were right-handed as assessed through the Edinburgh Handedness Inventory (mean lateraity quotient $=.80$; Oldfield, 1971). Exclusively right-handed males were tested in this and in the following experiments because they generally exhibit more consistent functional asymmetries than do females and left-handed males (see, e.g., Hellige, 1993).

\section{Design}

Four within-subjects variables were manipulated: context between initial encoding and subsequent test (same context vs. different context), letter case between initial encoding and subsequent test (same case vs. different case), hemisphere of test presentations ( $\mathrm{LH}$ vs. RH), and letter case of test presentations (lowercase vs. uppercase).

\section{Materials}

Ninety-six cue-target word pairs served as critical items. All words were nouns selected from the Kučera and Francis (1967) volume, and each word was always either a cue word or a target word. All cue words satisfied the following criteria: (1) Each was between 4 and 10 letters in length and of medium frequency in the language (mean number of occurrences per million $=64$; range $=$ 3-232; Kučera \& Francis, 1967); and (2) half of the cue words were highly concrete according to the Paivio, Yuille, and Madigan (1968) norms (mean concreteness rating $=6.84$; range $=6.25$ 7.70 ), and the other half were not (mean concreteness rating = 2.07 ; range $=1.18-2.95$ ).

All target words satisfied the following criteria: (1) The threeletter word stem of each target word (its first three letters) was unique among the set of all words used in the experiment; (2) the stem of each target word could be used to complete at least 10 common English words; (3) each target word was between 4 and 10 letters in length and of medium frequency in the language (mean number of occurrences per million $=64$; range $=4-244$; Kučera \& Francis, 1967); and (4) an experimenter judged that half of the target words were relatively concrete but the other half were not.

The cues and targets were combined to form word pairs so that only weak semantic associations existed between the words in a pair (in both same- and different-context pairings) and both words in a pair (again, in both same- and different-context pairings) were judged to be either concrete or not. Concreteness was not manipulated as an experimental variable to be tested; instead, half concrete and half nonconcrete pairs were used only to assure that we 
did not unintentionally use more of one kind than another in the experiment. Furthermore, 10 additional cue words and word stems were selected to form 10 practice pairs of one cue word and one stem each. Each practice cue word satisfied the constraints of the critical cue words, and each practice stem satisfied the word-stem constraints of the critical target words. Finally, five word pairs were used as buffer items in the encoding phase (three appearing at the beginning and two at the end of each encoding phase list) to attenuate primacy and recency effects.

The 96 critical word pairs were divided into 32 sublists of 3 pairs each. For each participant, 16 of the 32 sublists were used for stimuli in the encoding phase as well as for stimuli in the test phase (these were old test items), and the other 16 sublists were used for stimuli in the test phase but not in the encoding phase (these were new test items). New items were presented in the test phase to measure baseline probabilities of completing the word stems using the critical target words, without those words having been presented earlier in the experiment.

In order to counterbalance old items across participants, the 16 old sublists were rotated through the 16 conditions defined by orthogonally combining context between initial encoding and subsequent test (same context vs. different context), letter case between encoding and test (same case vs. different case), hemisphere of test presentations (LH vs. RH), and letter case of test presentations (lowercase vs. uppercase). Thus, each sublist represented each of these conditions an equal number of times across subjects. In addition, each sublist represented the old and new conditions an equal number of times across subjects. During the test phase, half of the new items were presented directly to the LH (half of these pairs in all lowercase letters and the other half in all uppercase letters), whereas the other half of the new items were presented directly to the $\mathrm{RH}$ (again, half of these pairs in all lowercase letters and the other half in all uppercase letters).

Therefore, for each participant, 16 of the sublists of items (48 pairs) that were presented during the test phase were old and the other 16 (48 pairs) were new. Eight of the 16 old sublists ( 24 pairs) were presented in the same cue-target pairings between the encoding phase and the test phase, and the other 8 of the 16 old sublists ( 24 pairs) were presented in different cue-target pairings between phases. Four of the 8 same-context and 4 of the 8 differentcontext sublists ( 12 pairs each) were presented in the same letter case between the encoding phase and the test phase (with two of these same-context sublists [six pairs] and two of these differentcontext sublists [six pairs] presented to the $\mathrm{LH}$ at test, and the other two of these same-context sublists [six pairs] and the other two of these different-context sublists [six pairs] presented to the RH at test). These items were the same-letter-case items. The other 4 of 8 same-context sublists and the other 4 of 8 different-context sublists ( 12 pairs each) were presented in the different letter case between the encoding phase and the test phase (again, with two of these same-context sublists [six pairs] and two of these differentcontext sublists [six pairs] presented to the LH at test, and the other two of these same-context sublists [six pairs] and the other two of these different-context sublists [six pairs] presented to the RH at test). These items were the different-letter-case items.

For all participants, the pairings of cue words and word stems used in the test phase were always the same. In order to create differentcontext encoding pairs, the pairings of cue and target words within one sublist were recombined within that sublist to form different pairings. These recombined pairs were presented to participants only during the encoding phase. In this way, the pairings of cue words and word stems utilized at test were the same in both the samecontext and different-context conditions for all participants. Furthermore, to validate that each of the original and recombined pairs had similarly weak semantic associations, we collected ratings from 16 naive judges. The items in each original and recombined pair had sufficiently weak associations that the judges could not rate the strength of association on a 5-point scale $(1=$ very weak;
$5=$ very strong) and distribute their ratings across the points. Thus, instead, each participant compared the original pair that includes a certain target word against the recombined pair that includes that target word and judged which pair had a stronger semantic relationship. They chose neither kind of pair more frequently than the other $(p>.50)$, assuring that similarly weak associations existed in the same- and different-context pairs.

The stimuli were presented on an AppleColor High Resolution RGB Monitor with a Polaroid CP-50 filter placed over it to reduce glare. Stimulus presentation and response time measurement were controlled by a Macintosh II or Macintosh IIfx computer. All letters were presented in black against a white background in a 24 point, Helvetica bold font (letter size varied, but was approximately $5 \times 6 \mathrm{~mm}$ for most letters). Both words in each word pair during the encoding phase and both the cue word and word stem during the test phase were presented in either all lowercase or all uppercase letters. A 2-mm dot (subtending $0.23^{\circ}$ of visual angle) served as the central fixation point that indicated the beginning of a trial. During the encoding phase, the word pairs appeared at the center of the monitor, with one word approximately $2 \mathrm{~mm}$ above the other and both words centered with respect to the monitor. In the test phase, the cue words and the word stems were presented in the same positions as they would have appeared in the encoding phase, with the following exceptions: The letters following the first three letters of each target word were deleted (to form a word stem), and each pair was presented in the left or right visual field so that the center of each pair was presented $4.57^{\circ}(4 \mathrm{~cm})$ from the center of the monitor, and the inner edge of any pair never appeared closer than $1.15^{\circ}$ $(1 \mathrm{~cm})$ from the center. Finally, a chinrest was used to keep a participant's eyes approximately $50 \mathrm{~cm}$ from the monitor.

\section{Procedure}

Each participant was tested individually in an experimental session that had two phases, an encoding phase and a test phase.

Encoding phase. In the encoding phase, participants silently read 48 word pairs (plus 5 filler word pairs, 3 at the beginning of the list and 2 at the end), 1 pair at a time. Participants determined whether the two words in each pair contained the same number of vowels. The vowel-counting task was used to encourage visualstructural processing of the word forms.

An encoding-phase trial began with the presentation of the fixation point, which appeared at the center of the screen for $500 \mathrm{msec}$. Immediately thereafter, a word pair appeared centrally for $6 \mathrm{sec}$, with the target word centered beneath the cue word. Participants pressed the "s" or " $\mathrm{d}$ " key on the computer keyboard to indicate whether the pair contained the same or a different number of vowels, respectively. They were instructed to deliver this response after the pair disappeared from the screen; thus presentation times were self-paced. The average presentation rate was about $7 \mathrm{sec}$ per word pair. The next trial began automatically $1 \mathrm{sec}$ after the "s" or " $\mathrm{d}$ " key was pressed.

Each participant viewed 16 sublists of word pairs in the encoding phase ( 48 word pairs) plus 5 filler pairs ( 3 at the beginning and 2 at the end of a list to attenuate primacy and recency effects). The list of 53 word pairs for each participant was presented twice in succession. Participants were told to follow the same instructions for the second iteration as those they had followed in the first. For each of the two successive list presentations for each participant, a different pseudo-random order was used. These orders were random with the constraints that no more than three pairs appeared consecutively in the same letter case, and that no more than three pairs appeared consecutively whose cue words and target word stems would be presented at test in the same or different context as at encoding, in the same or different letter case as at encoding, or in the same visual field.

Test phase. This phase began approximately $6 \mathrm{~min}$ after the encoding phase ended. A practice session of 10 trials conducted like test trials intervened between the encoding and test phases. Prac- 
tice was performed so that participants would become familiarized with the test procedure and with speaking responses into the microphone before the experimental trials began. Participants were instructed that in each test trial a word and a three-letter word stem would appear briefly, both to the left or right of the center of the monitor, with the word presented above the stem. They were told that each of the word stems was the beginning of an English word and that they were to add a few letters to each group to make a common English word and then immediately speak it aloud into the microphone. They were instructed to produce any English word but to report the first word that came to mind, excluding proper nouns. Furthermore, they were told that the context word above the stem might help them to think of a completion, but that it was unimportant whether the completion was related to the context word in any way

A test-phase trial began with the presentation of the fixation point at the center of the screen for $500 \mathrm{msec}$. Immediately after the fixation point disappeared, a cue word and a word stem appeared in the left or right visual field for $183 \mathrm{msec}$. The cue word always appeared above the word stem, and the three letters in the stem always appeared in the same position relative to the cue word that they would have occupied if they had been presented as part of a complete word centered below the cue word. A blank screen followed the presentation of the pair. Each trial was terminated by the registration of a spoken word via the microphone. Participants were instructed to focus their attention on the fixation point when it appeared and to speak aloud each word response as soon as they thought of it. They were also told that the computer would record the times it took them to respond and that the experimenter would record their responses. After a response was registered, 1 sec elapsed before the next trial began.

For each participant, all 32 sublists of word pairs were used to provide cue word and target word stem presentation pairs in the test phase ( 96 test pairs). However, the trials were presented in a different pseudo-random order for each participant. The orders were random with the constraints that no more than three old or three new test pairs appeared consecutively, and no more than three test pairs appeared in the same letter case, in the same or different context as at encoding (for old items), in the same or different letter case as at encoding (for old items), or in the same visual field.

\section{Results}

In all experiments reported in this article, each response word was scored as one of the 96 critical target words only if it was exactly the same as the critical word associated with the word stem presented in that trial. Thus, a strict scoring criterion was used. No plural forms, past tense forms, or other changes from an original critical word were accepted.

In a four-way repeated measures analysis of variance (ANOVA), we analyzed priming effects directly after computing difference scores. For each participant, we subtracted the critical-word completion rates for new items from the critical-word completion rates for old items. These rates for new items were $8.0 \%$ and $7.5 \%$ for lowercase and uppercase items presented directly to the $\mathrm{LH}$ and $9.9 \%$ and $8.6 \%$ for lowercase and uppercase items presented directly to the RH (these baseline rates did not differ significantly across test hemisphere or letter case of test presentations, $p s>.35$ ). Appropriate subtractions were calculated for each participant, in that the completion rates for the four new-item conditions (crossing two levels of test hemisphere and the two levels of letter case at test) were subtracted from the completion rates for the analogous old-item conditions. These subtractions produced "priming scores," which served as the dependent variable, allowing us to measure and analyze priming per se in a direct manner. Context between initial encoding and subsequent test (same context vs. different context), letter case between initial encoding and subsequent test (same case vs. different case), test hemisphere (LH vs. $\mathrm{RH}$ ), and letter case of test presentations (lowercase vs. uppercase) were within-subjects independent variables. ${ }^{4}$

Figure 1 illustrates the priming scores from this experiment. The important result was that the interaction between letter case (between encoding and test) and test hemisphere was marginally significant in the same-context trials $\left[F(1,62)=3.80, M S_{\mathrm{e}}=504.4, p<.06\right]$ for the interaction contrast (cf. Rosenthal \& Rosnow, 1985), but did not approach significance in the different-context trials $(F<1.0)$ for the interaction contrast. In fact, when samecontext items were presented directly to the RH, samecase priming $(15.3 \%)$ was significantly greater than different-case priming $(1.3 \%)\left[F(1,124)=12.3, M S_{\mathrm{e}}=\right.$ $514.0, p<.001]$ for the simple effect contrast. However, when same-context items were presented directly to the LH, same-case priming (9.1\%) was not significantly greater than different-case priming $(6.0 \%)(F<1.0)$ for the simple effect contrast. Also, when different-context items were presented directly to the $\mathrm{RH}$, same-case priming $(7.5 \%)$ was not significantly greater than differentcase priming $(6.0 \%)(F<1.0)$ for the simple effect contrast; and when different-context items were presented directly to the LH, same-case priming $(8.1 \%)$ was not significantly greater than different-case priming $(2.8 \%)$ $\left[F(1,124)=2.04, M S_{\mathrm{e}}=514.0, p>.15\right]$ for the simple effect contrast. Thus, the three-way interaction among context, letter case (between encoding and test), and test hemisphere was marginally significant $\left[F(1,31)=4.02, M S_{\mathrm{e}}=\right.$ $455.1, p<.06]$.

The only other significant effect in this analysis was the main effect of letter case between encoding and test (all other $p \mathrm{~s}>.15)$. Same-case priming $(10.0 \%)$ was reliably greater than different-case priming $(3.9 \%)[F(1,31)=$ $\left.9.37, M S_{\mathrm{e}}=511.4, p<.01\right]$. It is important to note that the main effect of context did not approach significance. Same-context priming $(7.9 \%)$ was not significantly greater than different-context priming $(6.0 \%)$ overall $(F<1.0)$.

\section{Discussion}

As predicted, in word-stem completion, letter-casespecific priming was observed in RH test presentations only when the word presented above the stem was the same word presented above the primed completion word during initial encoding. Letter-case-specific priming was not obtained in RH trials when a different-context word appeared above the stem. Furthermore, letter-casespecific priming was not observed in $\mathrm{LH}$ trials in the same- or different-context conditions. These results indicate that a subsystem that operates more effectively in 


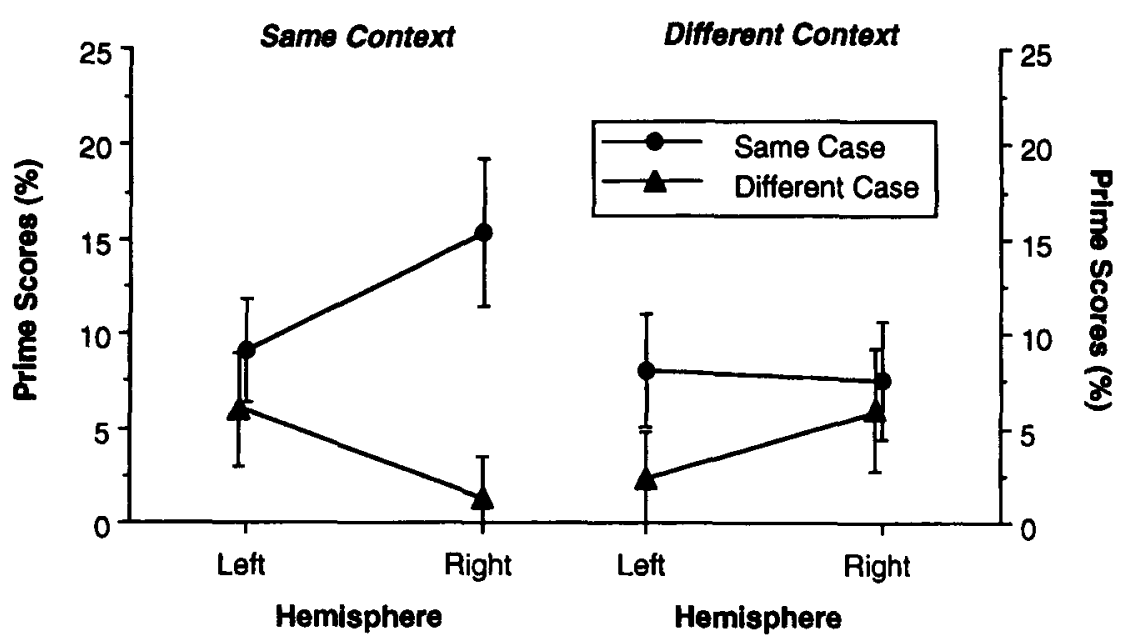

Figure 1. Word-stem completion priming results from Experiment 1A. Mean priming scores (critical-word completion rates when the stems could have been completed to form previously presented critical words minus critical-word completion rates when the critical words were not previously presented) are presented as a function of context between initial encoding and subsequent test (same context vs. different context), letter case between initial encoding and subsequent test (same case vs. different case), and hemisphere of test presentation (left hemisphere vs. right hemisphere). Error bars indicate standard errors of the mean.

the $\mathrm{RH}$ than in the LH stores form-specific information and information about novel holistic structures (i.e., the same subsystem that stores SVF information also stores information about both the context form and the target form in the same representation). These properties are characteristic of a subsystem that performs holistic processing to accomplish SVF processing. Thus, an SVF subsystem that operates more effectively in the RH than in the LH appears to perform holistic processing, not parts-based processing.

Although context did interact with letter case (between encoding and test) and hemisphere of test presentation in a three-way interaction, same-context priming generally was not greater than different-context priming in a main effect. This is an important result because the interaction is a novel finding, yet the main effect replicates earlier results. In this experiment, vowel counting was performed during initial encoding. Past research indicates that a main effect of context is not found when participants perform a nonconceptual encoding task like vowel counting (Graf \& Schacter, 1985; Schacter \& Graf, 1986a; but see Micco \& Masson, 1991), even though a main effect is found when participants perform a conceptual encoding task like generating sentences that meaningfully relate the pair words (Graf \& Schacter, 1985, 1987, 1989; Schacter \& Graf, 1986a, 1989). In addition, some amnesic patients exhibit impaired context effects in this paradigm (Cermak, Bleich, \& Blackford, 1988; Schacter \& Graf, 1986b; Shimamura \& Squire, 1989), and the effects they do exhibit are correlated with word fluency measures (Mayes \& Gooding, 1989). Finally, normal participants exhibit decreased context effects in this paradigm when cue words are homographs that are given different interpretations at test and encoding (Micco \& Masson, 1991). These findings indicate that context ef- fects in this paradigm are not supported solely by perceptual subsystems.

We suggest that the main effects of context in the earlier experiments were supported by amodal and multimodal information stored in conceptual systems in addition to visual information stored in perceptual subsystems (see also Schacter, 1990; Tulving \& Schacter, 1990). However, in the present experiment, structural changes in an SVF subsystem likely supported the effect of context in a three-way interaction. A conceptual system likely did not contribute to this context effect, because participants performed nonconceptual encoding and the brief visual presentation of each test stimulus probably encouraged participants to concentrate on perceptual processing of each stimulus.

Typically, priming effects in word-stem completion experiments are expressions of implicit memory. This is a form of memory that is exhibited when previously encoded information facilitates performance in a cognitive task, yet the facilitation is not influenced by deliberate recollection of the previously encoded information. In contrast, the form of memory that is exhibited when memory performance requires deliberate recollection of previous learning events is explicit memory (Graf \& Schacter, 1985). Participants in this experiment were asked to complete stems using the first words that came to mind, and they were not asked to recollect previously presented words. Thus, we assume that implicit memory was expressed. We test this assumption in Experiment 1B.

An SVF subsystem is one of many subsystems that store perceptual, conceptual, or motoric information in neocortical regions of the brain (Damasio, 1989; Gabrieli, Milberg, Keane, \& Corkin, 1990; Kosslyn, 1987; Marsolek et al., 1994; Petersen \& Fiez, 1993; Schacter, 1990; Squire, 1987; Tulving \& Schacter, 1990; Ungerleider \& 
Mishkin, 1982). For a short time after such a subsystem produces a particular output in response to receiving a particular input, structural changes cause the same inputoutput mapping (or a very similar mapping such as in primed word-stem completion) to take place more efficiently than it would if the prime event had not taken place. This facilitation likely accounts for repetition priming and many implicit memory effects. Importantly, processing in the hippocampal formation and related structures is not necessary for repetition priming effects; however, interactions between these structures and neocortical subsystems are necessary to store functional links between to-be-remembered information and unique elements of the encoding situation (see, e.g., several chapters in Schacter \& Tulving, 1994), as needed for explicit memory expression. Accordingly, neocortical subsystems store information that can be used to support both priming and explicit memory, albeit in different ways (see also Marsolek et al., 1994).

We reason that information stored in an SVF subsystem supports implicit memory but not explicit memory under the conditions used in the experiments reported in this article. An SVF subsystem likely supports explicit memory expression only when it is useful as a strategy to retrieve information explicitly from an SVF subsystem. Recent evidence suggests that this occurs when relatively few items are tested, a relatively short time intervenes between encoding and test, and all of the test items are presented in the same letter case as during encoding (see Marsolek et al., 1994; Schacter, Alpert, Savage, Rauch, \& Alpert, 1996; Squire et al., 1992). Under these conditions, cued recall of SVF information is obtained when stems are presented directly to the RH (Marsolek et al., 1994), and such a finding should be supported by information stored in an SVF subsystem through interaction with the hippocampal formation and related structures. However, in most priming experiments, a more effective strategy is to retrieve information from a conceptual system than from an SVF subsystem. In the present experiments, like most priming experiments (e.g., Marsolek et al., 1992), a relatively large number of items are tested, a relatively long retention interval is used, and not all of the test items are in the same letter case as during encoding. Under these conditions, cued recall of SVF information is not obtained when stems are presented directly to the RH (Marsolek et al., 1992). Therefore, we reason that the interesting results from Experiment $1 \mathrm{~A}$ are supported by information stored in an SVF subsystem, independently of the hippocampal system, and these results reflect implicit memory but not explicit memory. We tested this reasoning in the next experiment.

\section{EXPERIMENT 1B}

The procedure in this experiment was the same as that in Experiment 1 A except that we measured explicit memory through word-stem cued recall. Participants recalled words that had been presented during initial encoding to help them complete test stems. In all other respects, the procedure was the same as that in Experiment 1A. In particular, vowel counting was performed during encoding.

The results from this experiment should be qualitatively different from those of Experiment $1 \mathrm{~A}$. We should not find an interaction between case and test hemisphere (same-case cued recall greater than different-case cued recall only in RH trials) in the same-context condition. Although an SVF subsystem stores information that supports implicit memory under many conditions (Marsolek et al., 1992, 1994), this subsystem appears to support explicit memory only under certain conditions that are not present in the experiments reported in this article (see Marsolek et al., 1994; Schacter et al., 1996; Squire et al., 1992). Thus, the results from Experiment $1 \mathrm{~A}$ likely do not reflect explicit memory and should not be found in this cued recall experiment.

\section{Method}

\section{Participants}

Sixteen male Harvard University students volunteered as paid participants. All were native English speakers and right-handed as assessed through the Edinburgh Handedness Inventory (mean laterality quotient $=.72$; Oldfield, 1971). None participated in any other experiment in this study.

\section{Materials and Procedure}

The materials and procedure in this experiment were the same as those in Experiment $1 \mathrm{~A}$, with the following exceptions: In the test phase, participants were asked to recall words that they had previously seen during the exposure phase, using the word stems as cues. Thus, they were asked to complete the stems to form words that had appeared during the vowel-counting task. They were instructed to guess when they could not think of such words, and they were told that not all of the stems could possibly be completed to form previously presented words. Finally, for each of the 10 practice trials, participants were asked to report only the three letters in the word stem, because none of the practice stems could have been completed to form previously presented words.

\section{Results}

We analyzed cued recall performance by computing difference scores similar to those in Experiment 1A. For each participant, the critical-word completion rates for new items were subtracted from the critical-word completion rates for old items in the same manner as in Experiment $1 \mathrm{~A}$. The rates for new items were $10.1 \%$ and $9.5 \%$ for lowercase and uppercase items presented directly to the $\mathrm{LH}$ and $9.7 \%$ and $10.0 \%$ for lowercase and uppercase items presented directly to the RH (these baseline rates did not differ significantly across test hemisphere or letter case of test presentations, $p s>.80$ ). Using difference scores allowed us to analyze cued recall performance without the possible contamination produced by critical-word responses when those critical words had not been presented during the initial exposure phase. Thus, in a three-way repeated measures ANOVA, cued recall score was the dependent variable. Context between initial encoding and subsequent test (same context vs. different context), letter case between encoding and test (same case vs. different case), and test hemisphere (LH vs. RH) were within-subjects independent variables. 
Figure 2 depicts the cued recall scores from this experiment. In contrast with results from Experiment 1 A, the interaction between letter case (between encoding and test) and test hemisphere did not approach significance in the same-context trials $(F<1.0)$ for the interaction contrast or in the different-context trials $(F<1.0)$ for the interaction contrast. In fact, the only condition in which same-case cued recall was marginally greater than different-case cued recall was when same-context items were presented directly to the $\mathrm{LH}(19.3 \%$ vs. $5.8 \%$, respectively) $[F(1,60)=$ $\left.3.92, M S_{\mathrm{e}}=374.9, p<.06\right]$ for the simple effect contrast. The three-way interaction among context, letter case (between encoding and test), and test hemisphere did not approach significance $(F<1.0)$.

No main effects or interaction effects were significant in this analysis (all $p s>.10$ ). In particular, same-case cued recall $(14.5 \%)$ was not reliably greater than different-case cued recall $(8.3 \%)\left[F(1,15)=2.88, M S_{\mathrm{e}}=867.9\right.$, $p>.10]$ and same-context cued recall $(14.1 \%)$ was not reliably greater than different-context cued recall $(8.6 \%)$ $\left[F(1,15)=2.30, M S_{\mathrm{e}}=833.6, p>.15\right]$.

\section{Discussion}

In an explicit memory experiment, letter-case-specific cued recall was not obtained in RH test presentations when the word presented above the stem was the same word presented previously above the correct recall word. In fact, a trend for letter-case-specific cued recall was obtained only in LH test presentations in the same-context condition, a trend in the opposite direction to that of the analogous priming results from Experiment $1 \mathrm{~A}$. In that experiment, letter-case-specific priming was found in RH trials, but not in LH trials, in the same-context condition. Together, these findings indicate that an SVF sub- system supported the priming effects in Experiment 1A but did not support explicit memory performance under the conditions of these experiments.

In the next experiment, we attempted to replicate the findings from Experiment $1 \mathrm{~A}$, using other nonconceptual encoding tasks. Past research indicates that same-context priming is not greater than different-context priming in a main effect when participants perform nonconceptual encoding (Graf \& Schacter, 1985; Schacter \& Graf, 1986a; but see Micco \& Masson, 1991), as we found in Experiment $1 \mathrm{~A}$. Yet, in that experiment, the pattern of results obtained in same-context priming (letter-case-specific priming following $\mathrm{RH}$ but not $\mathrm{LH}$ test presentations) was not found in different-context priming. Thus, we judged it prudent to test whether the important pattern of results from Experiment $1 \mathrm{~A}$ would be obtained again when different nonconceptual encoding tasks are used.

\section{EXPERIMENT 2A}

This experiment was conducted similarly to Experiment $1 \mathrm{~A}$, except that participants performed different nonconceptual encoding tasks. Half of the participants counted the number of letters in each word pair that had structures defining enclosed spaces (e.g., $a, b$, and $d$ have enclosed spaces, whereas $c, f$, and $h$ do not). The other half of the participants rated which of the words per pair was more easily readable, following a task used by Graf and Ryan (1990). We assumed that both of these tasks require structural processing of the word forms, but not conceptual processing.

The results in this experiment should replicate the priming results obtained in Experiment 1A. Letter-casespecific priming should be found in $\mathrm{RH}$ test presentations

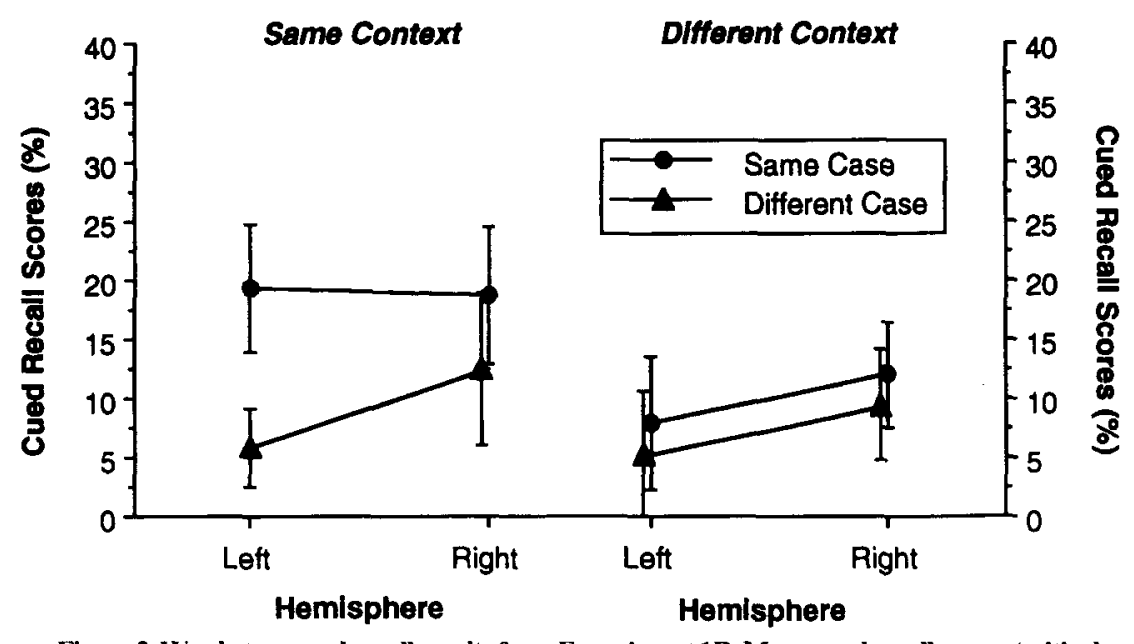

Figure 2. Word-stem cued recall results from Experiment 1B. Mean cued recall scores (criticalword recall rates when the stems could have been completed to form previously presented critical words minus critical-word completion rates when the critical words were not previously presented) are presented as a function of context between initial encoding and subsequent test (same context vs. different context), letter case between initial encoding and subsequent test (same case vs. different case), and hemisphere of test presentation (left hemisphere vs. right hemisphere). Error bars indicate standard errors of the mean. 
in the same-context condition but not in LH test presentations in either the same- or different-context conditions.

\section{Method}

\section{Participants}

Thirty-two male Harvard University students volunteered as paid participants. All were native English speakers and right-handed as assessed through the Edinburgh Handedness Inventory (mean laterality quotient $=.73$; Oldfield, 1971). None participated in any other experiment in this study.

\section{Materials and Procedure}

The materials and procedure were the same as those in Experiment $1 \mathrm{~A}$, with the following exceptions: Half of the participants performed an enclosed-letter counting task, and the other half performed a readability rating task during the encoding phase. For the enclosed-letter counting task, participants were asked to determine whether the two words in each pair contained the same number of "enclosed" letters. These were described as letters that are printed in such a manner that they form an enclosed space. " $A$ " and " $d$ " were used as examples of enclosed letters, and " $F$ " and " $m$ " were used as examples of letters that are not enclosed. Participants responded in the same manner as in Experiment IA. For the readability rating task, participants were asked to determine which of the two words in each pair was more easily "readable." They were asked to focus on the visual characteristics of each printed word (the shapes, font or typestyle, and letter case in which they were printed, etc.) that contributed to the ease with which it could be read. Participants responded by pressing the " $t$ " or " $b$ " key on the computer keyboard to indicate whether the top or bottom word was more easily readable, respectively. These tasks were used to encourage visual-structural processing of the word forms, but not conceptual processing of the words.

\section{Results}

As in Experiment 1A, we analyzed priming scores in a four-way repeated measures ANOVA. Critical-word completion rates for new items were $8.3 \%$ and $6.9 \%$ for lowercase and uppercase items presented directly to the LH and $9.7 \%$ and $6.4 \%$ for lowercase and uppercase items presented directly to the RH (these baseline rates did not differ significantly across test hemisphere or letter case of test presentations, $p \mathrm{~s}>.12$ ). Thus, priming score was the dependent variable. Type of encoding task (enclosed-letter counting vs. readability rating) was a between-subjects independent variable. Context between initial encoding and subsequent test (same context vs. different context), letter case between initial encoding and subsequent test (same case vs. different case), and test hemisphere ( $\mathrm{LH}$ vs. $\mathrm{RH}$ ) were within-subjects independent variables.

Figure 3 displays the priming scores from this experiment. Similar to results from Experiment 1A, the interaction between letter case (between encoding and test) and test hemisphere was significant in the same-context trials $\left[F(1,60)=5.58, M S_{\mathrm{e}}=342.1, p<.05\right]$ for the interaction contrast, but was not significant in the different-context trials $(F<1.0)$ for the interaction contrast. In fact, when same-context ilems were presented directly to the $\mathrm{RH}$, same-case priming $(16.8 \%)$ was significantly greater than different-case priming $(2.4 \%)[F(1,120)=$ $\left.8.81, M S_{\mathrm{e}}=376.7, p<.01\right]$ for the simple effect contrast. However, when same-context items were presented directly to the $\mathrm{LH}$, same-case priming $(14.0 \%)$ was not greater than different-case priming $(15.1 \%)$ for the simple effect contrast $(F<1.0)$. Furthermore, when differentcontext items were presented directly to the $\mathrm{RH}$, samecase priming $(12.0 \%)$ was not significantly greater than different-case priming $(9.4 \%)$ for the simple effect contrast $(F<1.0)$; and when different-context items were presented directly to the $\mathrm{LH}$, same-case priming $(11.7 \%)$ was not significantly greater than different-case priming $(9.1 \%)$ for the simple effect contrast $(F<1.0)$. The three-

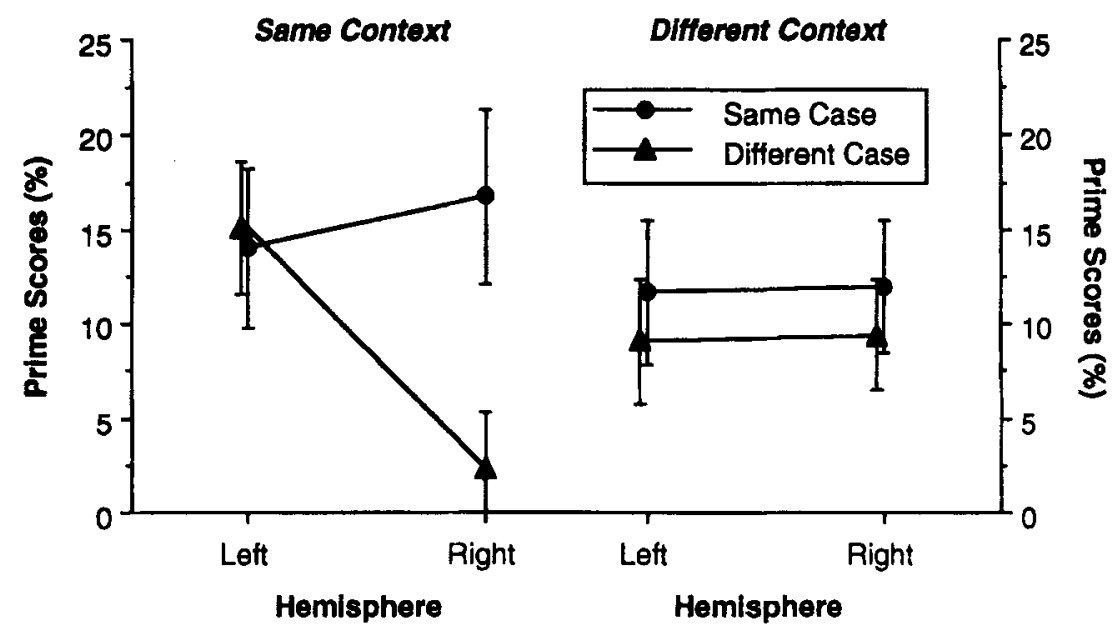

Figure 3. Word-stem completion priming nesults from Experiment 2A. Mean priming scores (critical-word completion rates when the stems could have been completed to form previously presented critical words minus critical-word completion rates when the critical words were not previously presented) are presented as a function of context between initial encoding and subsequent test (same context vs. different context), letter case between initial encoding and subsequent test (same case vs. different case), and hemisphere of test presentation (left hemisphere vs. right hemisphere). Error bars indicate standard errors of the mean. 
way interaction among context, letter case (between encoding and test), and test hemisphere approached significance $\left[F(1,30)=3.33, M S_{\mathrm{e}}=286.8, p<.08\right]$.

Same-case priming $(13.6 \%)$ was not reliably greater than different-case priming $(9.0 \%)$ in a main effect $[F(1,30)=$ $\left.2.70, M S_{\mathrm{e}}=509.9, p>.10\right]$. However, the interaction between type of encoding and letter case (between encoding and test) approached significance $\left[F(1,30)=3.51, M S_{\mathrm{e}}=\right.$ $509.9, p<.08]$. In this interaction, same-case priming $(13.8 \%)$ was somewhat greater than different-case priming (3.8\%) following readability ratings, whereas same-case priming $(13.5 \%)$ was not greater than different-case priming $(14.1 \%)$ following enclosed-letter counting. No other effects approached significance (all other $p \mathrm{~s}>.10$ ). In particular, it is important to note that same-context priming $(12.1 \%)$ was not reliably greater than different-context priming $(10.5 \%)$ in a main effect $(F<1.0)$.

\section{Combined Results From Experiments 1A and 2A}

In both Experiments $1 \mathrm{~A}$ and $2 \mathrm{~A}$, the three-way interaction among context, letter case, and test hemisphere was marginally significant. Apparently, the effect is not large but may be consistent. In order to directly assess the reliability of this important effect, we combined these interaction results from the two experiments, using the meta-analytic procedures recommended in Rosenthal (1978). Following Rosenthal's suggestion, we used three different methods to combine the results, because the number of studies is small (two). In all three methods, the effect was reliable: For the method of adding logs (i.e., Fisher method), $\chi^{2}(4)=10.9, p=.027$; for the method of adding probabilities, $p=.009$; and for the method of adding $Z s, p=.016$.

\section{Discussion}

The results from this experiment replicated those from Experiment 1A, and a meta-analysis of the two studies indicates that the important results were reliable across experiments. Letter-case-specific priming was observed in RH test presentations when the word presented above the stem was the same word that had been presented above the primed completion word during initial encoding. Letter-case-specific priming was not observed in $\mathrm{RH}$ test presentations in the different-context condition (or in LH test presentations). ${ }^{5}$ These findings support the hypothesis that an SVF subsystem performs holistic processing to store form-specific information.

Next, we tested whether the results from this experiment reflect explicit memory. In an experiment that is similar to this priming experiment, we investigated wordstem cued recall.

\section{EXPERIMENT 2B}

This experiment was conducted in the same manner as Experiment $2 \mathrm{~A}$ except that explicit memory was measured through word-stem cued recall. Participants re- called words that had been presented during initial encoding to help them complete test stems. For reasons similar to those that motivated us to conduct Experiment $1 \mathrm{~B}$, we predicted that the results from this experiment should be qualitatively different from the results of Experiment $2 \mathrm{~A}$, in which implicit memory was measured. In particular, there should not be an interaction between case and test hemisphere (greater same-case cued recall than different-case cued recall in RH but not in LH presentations) in the same-context condition.

\section{Method}

\section{Participants}

Thirty-two male Harvard University students volunteered as paid participants. All were native English speakers and righthanded as assessed through the Edinburgh Handedness Inventory (mean laterality quotient $=.78$; Oldfield, 1971). None participated in any other experiment in this study.

\section{Materials and Procedure}

The materials and procedure were the same as those in Experiment $2 \mathrm{~A}$, with the exception that participants followed the cuedrecall test instructions that were used in Experiment $1 \mathrm{~B}$. They were asked to recall words that they had seen during the encoding phase, using the word stems as cues.

\section{Results}

We analyzed cued recall performance by first computing difference scores, as in Experiment 1B. Criticalword completion rates for new items were $11.0 \%$ and $9.1 \%$ for lowercase and uppercase items presented directly to the LH and $10.7 \%$ and $10.0 \%$ for lowercase and uppercase items presented directly to the $\mathrm{RH}$ (these baseline rates did not differ significantly across test hemisphere or letter case of test presentations, $p s>.45$ ). Thus, cued recall score was the dependent variable in a fourway repeated measures ANOVA. Type of encoding task (enclosed-letter counting vs. readability rating) was a between-subjects independent variable. Context between initial encoding and subsequent test (same context vs. different context), letter case between encoding and test (same case vs. different case), and test hemisphere ( $\mathrm{LH}$ vs. $\mathrm{RH}$ ) were within-subjects independent variables.

Figure 4 shows the cued recall scores from this experiment. In contrast with Experiment 2A, the interaction between letter case (between encoding and test) and test hemisphere did not approach significance in the samecontext trials $(F<1.0)$ for the interaction contrast or in the different-context trials $(F<1.0)$ for the interaction contrast. Same-case cued recall was not greater than differentcase cued recall in any condition (all $p s>.20$ ). Thus, the three-way interaction among context, letter case (between encoding and test), and test hemisphere did not approach significance $(F<1.0)$.

Only one effect was significant in this analysis (all other $p \mathrm{~s}>.10$ ). In a main effect, cued recall following the readability rating task was greater than cued recall following the enclosed-letter counting task $(20.0 \%$ vs. $7.5 \%$, respectively) $\left[F(1,30)=11.7, M S_{\mathrm{e}}=858.2, p<.01\right]$. It is 
important to note that same-case cued recall $(15.7 \%)$ was not reliably greater than different-case cued recall $(11.8 \%)$ $\left[F(1,30)=2.73, M S_{\mathrm{e}}=358.1, p>.10\right]$ and that samecontext cued recall $(15.6 \%)$ was not reliably greater than different-context cued recall $(11.8 \%)[F(1,30)=2.08$, $\left.M S_{\mathrm{e}}=438.9, p>.15\right]$.

\section{Discussion}

As predicted, a different pattern of results was obtained in this explicit memory experiment compared with the previous implicit memory experiment. In particular, letter-case-specific cued recall was not obtained in RH test presentations when the word presented above the stem was the same word that had been presented earlier above the correct recall word, in contrast with the analogous priming results from Experiment $2 \mathrm{~A}$. These differences parallel the different results obtained in Experiments $1 \mathrm{~A}$ and $1 \mathrm{~B}$; thus whatever subsystems supported the priming effects in Experiments 1A and 2A apparently did not contribute to explicit memory performance in Experiments $1 \mathrm{~B}$ and $2 \mathrm{~B}$. These findings support the hypothesis that an SVF subsystem underlies letter-casespecific priming in same-context trials in Experiments $1 \mathrm{~A}$ and $2 \mathrm{~A}$, but not explicit memory in Experiments $1 \mathrm{~B}$ and $2 \mathrm{~B}$.

However, in each of the previous experiments a relatively small number of observations per cell was used. Six observations per participant were gathered in each of the old-item conditions that entered into the difference scores plotted in Figures 1-4. Because of this relatively small number, on average, only a one-item difference produced the letter-case effects in same-context RH trials in Experiments $1 \mathrm{~A}$ and 2A. Such a small difference (one item), when expressed as a relatively large propor- tion (1/6), could compromise differences that did not reach significance, but may reflect theoretically important effects. For this reason, we conducted a final experiment to attempt to replicate the important results from Experiments $1 \mathrm{~A}$ and $2 \mathrm{~A}$ when a larger number of observations per cell was collected.

\section{EXPERIMENT 3}

This experiment was conducted in the same manner as Experiment $1 \mathrm{~A}$, except that all words and words stems were presented in all uppercase letters throughout the experiment. In this way, only same-case priming was examined. The only priming variables in this experiment were context between encoding and test and hemisphere of test presentations; thus there were more observations per cell in the analysis for this experiment than in the previous experiments.

We hypothesized that much of the priming in this experiment would be supported by structural changes in an SVF subsystem because only same-case priming was examined. If this subsystem supports priming for novel holistic structures and operates more effectively in the $\mathrm{RH}$ than in the $\mathrm{LH}$, we should find an interaction between context and hemisphere, with greater same-context priming than different-context priming following $\mathrm{RH}$, but not following $\mathrm{LH}$, test presentations.

Method
Participants
Forty-eight male University of Arizona undergraduates partici-
pated for course credit. All were native English speakers and right-
handed as assessed through the Edinburgh Handedness Inventory
(mean laterality quotient $=.73$; Oldfield, 1971). None had partic-
ipated in any of the previous experiments.

\section{Method}

Participants

pated for course credit. All were native English speakers and righthanded as assessed through the Edinburgh Handedness Inventory ipated in any of the previous experiments.

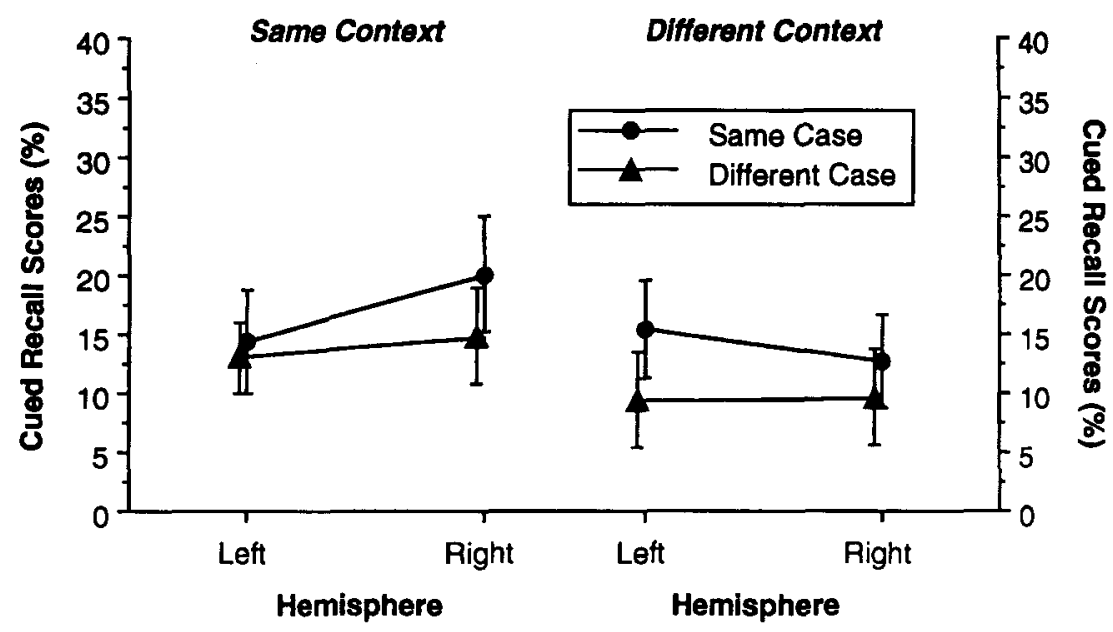

Figure 4. Word-stem cued recall results from Experiment 2B. Mean cued recall scores (criticalword recall rates when the stems could have been completed to form previously presented critical words minus critical-word completion rates when the critical words were not previously presented) are presented as a function of context between initial encoding and subsequent test (same context vs. different context), letter case between initial encoding and subsequent test (same case vs. different case), and hemisphere of test presentation (left hemisphere vs. right hemisphere). Error bars indicate standard errors of the mean. 


\section{Design}

Two within-subjects variables were manipulated: context between initial encoding and subsequent test (same context vs. different context) and hemisphere of test presentations ( $\mathrm{LH}$ vs. RH).

\section{Materials and Procedure}

The materials and procedure were the same as those in Experiment $1 \mathrm{~A}$, except that all words and word stems were presented in all uppercase letters throughout the experiment. Thus, all 48 pairs of old test items were presented in the same letter case as during initial encoding, and of these, 24 were presented in the same cuetarget pairings between the encoding and the test phase (12 in the left visual field, and 12 in the right visual field), and the other 24 were presented in different cue-target pairings between phases ( 12 in the left visual field, and 12 in the right visual field).

\section{Results}

Critical-word completion rates for new items were $9.4 \%$ for items presented directly to the $\mathrm{LH}$ and $9.5 \%$ for items presented directly to the $\mathrm{RH}$ (these baseline rates did not differ significantly across test hemisphere, $p>.95$ ). Priming score was the dependent variable, as in the previous priming experiments. Context between initial encoding and subsequent test (same context vs. different context) and test hemisphere (LH vs. RH) were the within-subjects independent variables. Unlike in the previous experiments, there were few enough conditions and a large enough number of participants in this experiment to allow for a valid analysis using items as the random variable. Thus, we analyzed priming effects in separate two-way repeated measures ANOVAs using subjects $\left(F_{1}\right)$ and items $\left(F_{2}\right)$ as the random variables.

The priming scores from this experiment are shown in Figure 5. The important result was that the interaction between context and test hemisphere was significant $\left[F_{1}(1,47)=5.33, M S_{\mathrm{e}}=96.9, p<.05 ; F_{2}(1,95)=6.87\right.$, $M S_{\mathrm{e}}=213.8, p<.05$ ]. Simple effect contrasts revealed that for items presented to the RH, same-context priming $(14.2 \%)$ was significantly greater than different-context priming $(6.9 \%)\left[F_{1}(1,94)=10.3, M S_{\mathrm{e}}=123.9, p<.01\right.$; $\left.F_{2}(1,190)=11.6, M S_{\mathrm{e}}=283.9, p<.01\right]$. However, for items presented to the $\mathrm{LH}$, same-context priming $(9.0 \%)$ was not significantly greater than different-context priming $(8.2 \%)\left(F_{1}<1.0, F_{2}<1.0\right)$ for the simple effect contrasts. In addition, for same-context items, priming was greater for items presented to the RH $(14.2 \%)$ than to the LH $(9.0 \%)$ in a marginally significant effect $\left[F_{1}(1,94)=\right.$ $\left.3.70, M S_{\mathrm{e}}=179.9, p<.06\right]$ and in a significant effect $\left[F_{2}(1,190)=5.62, M S_{\mathrm{e}}=323.8, p<.05\right]$ for the simple effect contrasts. For different-context items, priming was not significantly different for items presented to the $\mathrm{LH}$ $(8.2 \%)$ than to the RH $(6.9 \%)\left(F_{1}<1.0, F_{2}<1.0\right)$ for the simple effect contrasts.

The only other significant effect in this analysis (all other $p \mathrm{~s}>.25)$ was the main effect of context $\left[F_{1}(1,47)=\right.$ $5.15, M S_{\mathrm{e}}=151.1, p<.05, F_{2}(1,95)=5.17, M S_{\mathrm{e}}=354.0$, $p<.05$ ] indicating greater same-context priming $(11.6 \%)$ than different-context priming $(7.6 \%)$.

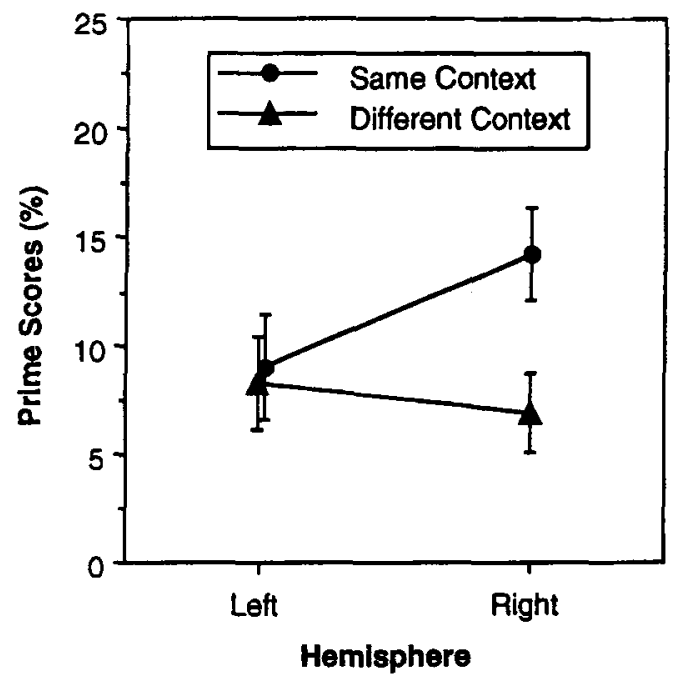

Figure 5. Word-stem completion priming results from Experiment 3. Mean priming scores (critical-word completion rates when the stems could have been completed to form previously presented critical words minus critical-word completion rates when the critical words were not previously presented) are presented as a function of context between initial encoding and subsequent test (same context vs. different context) and hemisphere of test presentation (left hemisphere vs. right hemisphere). All priming in this experiment was same-letter-case. Error bars indicate standard errors of the mean.

\section{Discussion}

The results from this experiment provided further evidence supporting our hypotheses. When only same-lettercase priming was examined, same-context priming was greater than different-context priming following $\mathrm{RH}$ test presentations but not following LH test presentations. These results support the hypothesis that an SVF subsystem operates more effectively in the RH than in the $\mathrm{LH}$ and that it stores information about novel holistic structures.

Another interesting result in this experiment is that same-context priming was greater than different-context priming in a main effect, unlike in Experiments $1 \mathrm{~A}$ and $2 \mathrm{~A}$. This suggests that context can affect stem-completion priming when a nonconceptual encoding task is performed, but perhaps only when same-case items are used throughout the experiment (unlike in Experiments 1A and 2A) and items are flashed briefly during the stem-completion test, encouraging a reliance on visual processing during the completion procedure (unlike in Graf \& Schacter, 1985; Schacter \& Graf, 1986a). Of course, this explanation invites further examination.

\section{GENERAL DISCUSSION}

We hypothesized that holistic processing, not partsbased processing, characterizes the operations in an SVF subsystem that operates more effectively in the RH than in the LH. A holistic processing strategy should be use- 
ful for storing the visually distinctive information that differentiates specific instances in the same abstract category of form and also for storing the new information in a novel form. Thus, we tested whether structural changes in an SVF subsystem support form-specific priming for novel holistic information. Consistent with our hypothesis, letter-case-specific priming in word-stem completion was obtained only when test items were presented directly to the RH and those items were presented in the same context as that in initial encoding. Furthermore, when same-case priming was examined in the final experiment, same-context priming was greater than differentcontext priming in RH test presentations but not in $\mathrm{LH}$ test presentations. In other words, the structural changes that support priming in an SVF subsystem also support priming for novel holistic information.

Although these results are inconsistent with the hypothesis that parts-based processing characterizes an SVF subsystem, we should stress that behavioral results alone cannot completely rule out this possibility. One might argue that these results are consistent with the idea that an SVF subsystem performs parts-based processing, if the represented parts capture the visually distinctive information that differentiates specific instances in the same abstract category of visual form, and if priming for novel holistic information is supported by structural changes in a (presumably final) stage of processing in which representations of whole forms are stored in terms of how those parts are related to each other. However, it is very important to note that because such a subsystem would store visually distinctive information and support priming for novel holistic structures to the same degree as a holistic processing subsystem, it would be functionally indistinguishable from such a subsystem. Furthermore, parts-based theories normally posit representations that capture relatively invariant features, not visually distinctive information, and a stage of processing (that should support much if not all of the priming in the subsystem) in which representations of the parts of a stimulus pair are stored independently as such before the whole of the pair is represented. Thus, a parts-based theory could account for the findings in this article only by compromising these vitally important features of that approach. This is why we conclude that parts-based processing does not characterize the operations in an SVF subsystem.

It is important to note that the visual field effects in these results are not compromised by the following apparent problems. First, the target word stems were always the first three letters of the target words and hence were always presented roughly on the left half of the computer monitor during encoding. Thus, one might argue that the stems in left-visual-field test trials were presented in the same half of visual space as they were during encoding, whereas the stems in right-visual-field trials were not. However, each word pair was presented for $6 \mathrm{sec}$ in the central visual field during encoding, so that, with eye movements, the visual information was projected directly to both hemispheres. Because visual information was presented directly to one hemisphere only during test trials, there was no confounding variable, and the above argument would not hold. Second, the strongly established left-to-right reading habit in most adults may make it easier to process information presented in the right visual field than in the left visual field during test, and the stem part of a test pair was presented closer to the fovea in right-visual-field than in left-visual-field trials. These points are not important for interpreting our results, however, because both produce situations favoring rightvisual-field trials, which works against our hypothesis and results. We found left-visual-field advantages for letter-case-specific same-context priming, as predicted. In any case, we emphasize that we are concerned mainly with testing interaction effects involving visual field at test, not main effects of visual field (cf. Hellige, 1983), using the reasoning in the Introduction.

The evidence supporting our hypothesis comes from priming for new associations between unrelated word forms. Although word-stem completion is a common paradigm for investigating priming for new associations (e.g., Bowers \& Schacter, 1990; Cermak et al., 1988; Graf \& Schacter, 1985, 1987, 1989; Howard, Fry, \& Brune, 1991; Mayes \& Gooding, 1989; Micco \& Masson, 1991; Schacter \& Graf, 1986a, 1986b, 1989; Shimamura \& Squire, 1989), such priming has been investigated using other paradigms as well. For example, Moscovitch, Winocur, and McLachlan (1986) and Musen and Squire (1993) examined facilitations in the time it takes to read word pairs that have recently been read. Priming is greater for pairs that remain intact between encoding and test than for pairs that are recombined. In addition, McKoon and Ratcliff $(1979,1986)$ and Goshen-Gottstein and Moscovitch (1995) investigated facilitations in making lexical decisions for words that have been viewed previously in the context of prime words. Greater priming is found when words are presented in the same context than in a different context, as before (but see also Bainbridge, Lewandowsky, \& Kirsner, 1993; Carroll \& Kirsner, 1982; Dagenbach, Horst, \& Carr, 1990; Neely \& Durgunoğlu, 1985; Durgunoğlu \& Neely, 1987; Smith, MacLeod, Bain, \& Hoppe, 1989). Depending on the particular strategies and information storage that result when different methodologies are used, new-associations priming may rely on storage of information in various subsystems. We argue that an SVF subsystem supports priming for new associations when a visual subsystem stores holistic information specifying a particular instance of visual form.

Our hypothesis that holistic processing characterizes an SVF subsystem that operates more effectively in the $\mathrm{RH}$ than in the LH is roughly consistent with previous theories that emphasize general aspects of lateralized analytical versus holistic processing (e.g., Bever, 1980; Bradshaw \& Nettleton, 1981; Corballis, 1989; Diamond \& Carey, 1986; Levine \& Calvanio, 1989). In addition, our hypothesis is consistent with several past findings 
and may help to illuminate interesting interpretations of them. First, hemispheric asymmetries have been found for processing low versus high spatial frequencies and relatively global versus local visual information. When higher level memory comparison processes are used in identification and discrimination tasks (as opposed to lower level processes in detection tasks), RH advantages are found for processing low spatial-frequency information and LH advantages are found for processing high spatial-frequency information (Christman, Kitterle, \& Hellige, 1991; Kitterle, Christman, \& Hellige, 1990; Kitterle \& Selig, 1991). A related finding may be that RH advantages are found for processing global forms of hierarchically arranged stimuli (e.g., a collection of small letter $S$ s positioned to form a larger letter $H$ ) and $\mathrm{LH}$ advantages are found for processing the local parts (Robertson \& Lamb, 1991; Van Kleeck, 1989). The low spatialfrequency information carried by the global forms may be responsible for the $\mathrm{RH}$ advantages for those forms (Sergent, 1982). Presumably, a subsystem that performs holistic processing of inputs should be sensitive to low spatial frequencies and relatively global information. Hence, these findings are consistent with our hypothesis. In fact, to account for past research using hierarchical stimuli, Robertson and Lamb (1991) suggested that a subsystem in posterior cortex of the $\mathrm{RH}$ effectively processes the global properties of these stimuli.

Second, several studies indicate that the RH plays an important role in face identification, an ability that an SVF subsystem may underlie. Faces are identified more effectively when presented directly to the RH than to the LH in divided-visual-field experiments (e.g., Geffen, Bradshaw, \& Wallace, 1971), although this RH advantage may be obtained consistently only when the faces are relatively unfamiliar (Sergent $\&$ Bindra, 1981). In a positron emission tomography experiment, a region of posterior cortex in the RH was selectively activated during face identification (Sergent, Ohtra, \& MacDonald, 1992). Furthermore, the inability to identify faces as a result of brain damage (prosopagnosia) has yet to be found when damage is restricted to the $\mathrm{LH}$ in a right-handed patient (Sergent et al., 1992). To the extent that storage of visually distinctive information is necessary for face identification and that faces must be processed in a relatively holistic manner to be identified (see Diamond \& Carey, 1986; Farah, 1991; Tanaka \& Farah, 1993), these findings are consistent with our hypothesis.

Third, evidence from brain-damaged patients is consistent with our hypothesis. Farah $(1990,1991)$ analyzed a large number of cases of associative agnosia, in which brain-damaged patients are impaired at visual recognition of stimuli but not at elementary visual perception of the same stimuli. The combinations of impaired abilities exhibited by individual patients indicate that two different types of visual recognition capacities can be disrupted by brain damage. Although Farah argued that both capacities rely on structural description, one is more effective at representing complex parts in a relatively holistic manner (useful for face identification and some kinds of object recognition) and the other is more effective at representing numerous, simple parts (useful for normal word recognition and some kinds of object recognition). Generally, the former capacity is impaired following damage to the $\mathrm{RH}$, and the latter capacity is impaired following damage to the $\mathrm{LH}$. Thus, the former capacity may be associated with an SVF subsystem.

Finally, Jolicoeur (1990) reviewed research on the identification of disoriented objects, concluding that two functionally separate systems may be involved. One uses a mental-rotation process to transform disoriented input forms before matching them against upright orientationspecific representations in storage. The other uses a feature-based process to compare shape attributes of input forms against more complete representations in storage. Because the former system is hypothesized to use a relatively more holistic processing mechanism than the latter system, the theory is consistent with our notion that an SVF subsystem performs holistic processing separately from an AVF subsystem.

Although we suggest that a subsystem based in the neocortex of the RH contributes to the case- and contextspecific priming effects reported here, it must be emphasized that we have no direct evidence that bears on which particular regions of the RH are crucial for SVF priming. For example, previous research indicates that some amnesic patients exhibit impaired priming of new associations in the stem completion task (Cermak et al., 1988; Schacter \& Graf, 1986b; Shimamura \& Squire, $1989)$ and also indicates impaired form-specific visual and auditory priming in amnesia (Kinoshita \& Wayland, 1993; Schacter, Church, \& Bolton, 1995). These results raise the possibility that the SVF priming for new associations that we report depends not only on neocortical regions of the $\mathrm{RH}$, but also on medial temporal regions of the RH that are typically damaged in amnesic patients (see, e.g., several chapters in Schacter \& Tulving, 1994). Indeed, Schacter (1994) drew a distinction between Type A priming-which involves abstract perceptual representations and occurs within posterior neocortical regions-and Type B priming, which involves highly specific perceptual associations and depends on medial temporal regions. However, one aspect of our results suggests that medial temporal regions of the $\mathrm{RH}$ are not involved in the SVF priming for new associations reported here. If they were, one would expect an RH advantage for SVF cued recall of new associations as well, yet we did not find such a result (note, however, that form-specific auditory priming is impaired in medialtemporal amnesia even though form-specific auditory explicit memory is not found in normal participants; Church \& Schacter, 1994; Schacter \& Church, 1992). It remains to be determined exactly which regions of the RH form the critical substrate of the priming effects described in this article (and whether Type A priming has both specific and abstract subcomponents).

To conclude, relatively independent neural subsystems perform SVF and AVF recognition. An SVF subsystem operates more effectively in the RH than in the 
LH and performs holistic processing, not parts-based processing, to store the visual information needed to distinguish specific instances in the same abstract category of form. These results help to place important constraints on our understanding of the architecture of visual memory and on our grasp of how unfamiliar visual forms are learned initially. In addition, they may help to constrain the application of different theoretical approaches (holistic versus parts-based processing) to different processing domains (SVF vs. AVF recognition). Indeed, both of these theoretical approaches may be needed to understand the diverse abilities in human vision and memory.

\section{REFERENCES}

Bainbridge, J. V., Lewandowsky, S., \& Kirsner, K. (1993). Context effects in repetition priming are sense effects. Memory \& Cognition, 21, 619-626.

Beeman, M., Friedman, R. B., Grafman, J., Perez, E., Diamond, S., \& LiNDSAY, M. B. (1994). Summation priming and coarse coding in the right hemisphere. Journal of Cognitive Neuroscience, 6, 26-45.

Bever, T. G. (1980). Broca and Lashley were right: Cerebral dominance is an accident of growth. In D. Kaplan \& N. Chomsky (Eds.), Biology and language (pp. 186-230). Cambridge, MA: MIT Press.

BIEDERMAN, I. (1987). Recognition-by-components: A theory of human image understanding. Psychological Review, 94, 115-147.

Biederman, I., \& CoOPer, E. E. (1991). Priming contour-deleted images: Evidence for intermediate representations in visual object recognition. Cognitive Psychology, 23, 393-419.

Bowers, J. S., \& SCHACTER, D. L. (1990). Implicit memory and test awareness. Journal of Experimental Psychology: Learning, Memory, \& Cognition, 16, 404-416.

Bradshaw, J. L., \& Nettleton, N. C. (1981). The nature of hemispheric specialization in man. Behavioral \& Brain Sciences, 4, 5191.

BrownELL, H. H. (1988). Appreciation of metaphoric and connotative word meaning by brain-damaged patients. In C. Chiarello (Ed.), Right hemisphere contributions to lexical semantics (pp. 19-31) Heidelberg: Springer-Verlag.

BRUCE, V., \& YOUNG, A. (1986). Understanding face recognition British Journal of Psychology, 77, 305-327.

BülthofF, H. H., \& EDElman, S. (1992). Psychophysical support for a two-dimensional view interpolation theory of object recognition. Proceedings of the National Academy of Sciences, 89, 60-64.

Burgess, C., \& Simpson, G. (1988). Cerebral hemispheric mechanisms in the retrieval of ambiguous word meanings. Brain \& Language, 33, 86-103.

BURGUnd, E. D., \& MARSOLEK, C. J. (1996). Letter-case specific priming in the right cerebral hemisphere with a form-specific perceptual identification task. Manuscript submitted for publication.

Carroll, M., \& Kirsner, K. (1982). Context and repetition effects in lexical decision and recognition memory. Journal of Verbal Learning \& Verbal Behavior, 21, 55-69.

Cermak, L. S., Bleich, R. P., \& Blackford, S. P. (1988). Deficits in the implicit retention of new associations by alcoholic Korsakoff patients. Brain \& Cognition, 7, 312-323.

Chiarello, C. (1991). Interpretation of word meanings by the cerebral hemispheres: One is not enough. In P. J. Schwanenflugel (Ed.), The psychology of word meanings (pp. 251-278). Hillsdale, NJ: Erlbaum.

Christman, S., Kitterle, F. L.. \& Hellige, J. B. (1991). Hemispheric asymmetry in the processing of absolute versus relative spatial frequency. Brain \& Cognition, 16, 62-73.

Church, B. A., \& Schacter, D. L. (1994). Perceptual specificity of auditory priming: Implicit memory for voice intonation and fundamental frequency. Journal of Experimental Psychology: Learning, Memory, \& Cognition, 20, 521-533.
Corballis, M. C. (1989). Laterality and human evolution. Psycholog ical Review, 96, 492-505.

Dagenbach, D., Horst, S., \& Carr, T. H. (1990). Adding new information to semantic memory: How much learning is enough to produce automatic priming? Journal of Experimental Psychology: Learning, Memory, \& Cognition, 16, 581-591.

Damasio, A. R. (1989). Time-locked multiregional retroactivation: A systems-level proposal for the neural substrates of recall and recognition. Cognition, 33, 25-62.

DiAMOND, R., \& CAREY, S. (1986). Why faces are and are not special An effect of expertise. Journal of Experimental Psychology: General, 115, 107-117.

DurgunoĞLu, A. Y., \& Neely, J. H. (1987). On obtaining episodic priming effects in a lexical decision task following paired-associate learning. Journal of Experimental Psychology: Learning, Memory. \& Cognition, 13, 206-222.

FARAH, M. J. (1990). Visual agnosia: Disorders of object recognition and what they tell us about normal vision. Cambridge, MA: MIT Press.

FARAH, M. J. (1991). Patterns of co-occurrence among the associative agnosias: Implications for visual object representation. Cognitive Neuropsychology, 8, 1-19.

Fox, P. T., Miezin, F. M., Allman, J. M., Van Essen, D. C., \& RAICHLE, M. E. (1987). Retinotopic organization of human visual cortex mapped with positron emission tomography. Journal of Neuroscience, 7, 913-922

Gabrieli, J. D. E., Milberg, W., Keane, M. M., \& Corkin, S. (1990). Intact priming of patterns despite impaired memory. Neuropsy. chologia, 28, 417-428.

GefFen, G., Bradshaw, J. L., \& Wallace, G. (1971). Interhemispheric effects on reaction time to verbal and nonverbal visual stimuli. Journal of Experimental Psychology, 85, 415-422.

Goshen-GotTstein, Y., \& Moscovitch, M. (1995). Repetition priming for newly formed and preexisting associations: Perceptual and conceptual influences. Journal of Experimental Psychology: Learning, Memory, \& Cognition, 21, 1229-1248.

GRAF, P., \& RYAN, L. (1990). Transfer-appropriate processing for implicit and explicit memory. Journal of Experimental Psychology. Learning, Memory, \& Cognition, 16, 978-992.

Graf, P., \& Schacter, D. L. (1985). Implicit and explicit memory for new associations in normal and amnesic subjects. Journal of Experimental Psychology: Learning, Memory, \& Cognition, 11, 501-518.

GRAF, P., \& SCHACTER, D. L. (1987). Selective effects of interference on implicit and explicit memory for new associations. Journal of Experimental Psychology: Learning, Memory, \& Cognition, 13, 4553.

GraF, P., \& Schacter, D. L. (1989). Unitization and grouping mediate dissociations in memory for new associations. Journal of Experimental Psychology: Learning, Memory, \& Cognition, 15, 930940.

Hellige, J. B. (1983). Hemisphere $\times$ task interaction and the study of laterality. In J. B. Hellige (Ed.), Cerebral hemispheric asymmetry: Method, theory, and research (pp. 411-443). New York: Praeger.

HELLIGE, J. B. (1993). Hemispheric asymmetry: What's right and what's left. Cambridge, MA: Harvard University Press

Howard, D. V., FrY, A. F., \& BRUNE, C. M. (1991). Aging and memory for new associations: Direct versus indirect measures. Journal of Experimental Psychology: Learning, Memory, \& Cognition, 17, 779792.

Hummel, J. E., \& Biederman, I. (1992). Dynamic binding in a neural network for shape recognition. Psychological Review, 99, 480-517.

Huttenlocher, D. P., \& Ullman, S. (1990). Recognizing solid objects by alignment with an image. International Journal of Computer Vision, 5, 195-212.

Jolicoeur, P. (1990). Identification of disoriented objects: A dualsystems theory. Mind \& Language, 5, 387-410.

KinOSHITA, S., \& WAYLAND, S. V. (1993). Effects of surface features on word-fragment completion in amnesic subjects. American Journal of Psychology, 106, 67-80.

Kitterle, F. L., Christman, S., \& Hellige, J. B. (1990). Hemispheric differences are found in the identification, but not the detection, of 
low versus high spatial frequencies. Perception \& Psychophysics, 48, 297-306.

KitTERLE, F. L., \& SELIG, L. M. (1991). Visual field effects in the discrimination of sine-wave gratings. Perception \& Psychophysics, 50, $15-18$.

KoIvisto, M. (1995). On functional brain asymmetries in perceptual priming. Brain \& Cognition, 29, 36-53.

KoIvisTo, M. (in press). Form-specific priming and functional brain asymmetries in perceptual identification. Cortex.

KosSLYN, S. M. (1987). Seeing and imagining in the cerebral hemispheres: A computational approach. Psychological Review, 94, 148175.

Kosslyn, S. M., Alpert, N. M., Thompson, W. L., Maljkovic, V., Weise, S. B., Chabris, C. F., Hamilton, S. E., Rauch, S. L., \& BuoNANNO, F. S. (1993). Visual mental imagery activates topographically organized visual cortex: PET investigations. Journal of Cognitive Neuroscience, 5, 263-287.

KUČERA, M., \& FRANCIS, W. (1967). Computational analysis of presentday American English. Providence, RI: Brown University Press.

Levine, D., \& Calvanio, R. (1989). Prosopagnosia: A defect in visual configural processing. Brain \& Cognition, 10, 149-170.

LowE, D. G. (1985). Perceptual organization and visual recognition. Boston: Kluwer.

LowE, D. G. (1987). Three-dimensional object recognition from single two-dimensional images. Artificial Intelligence, 31, 355-395.

MARR, D. (1982). Vision. San Francisco: W. H. Freeman.

MARR, D., \& NishihARA, H. K. (1978). Representation and recognition of the spatial organization of three-dimensional shapes. Proceedings of the Royal Society of London: Series B, 200, 269-294.

MARSOLEK, C. J. (1995). Abstract-visual-form representations in the left cerebral hemisphere. Journal of Experimental Psychology: Human Perception \& Performance, 21, 375-386.

Marsolek, C. J., Kosslyn, S. M., \& Squire, L. R. (1992). Formspecific visual priming in the right cerebral hemisphere. Journal of Experimental Psychology: Learning, Memory, \& Cognition, 18, 492 508 .

Marsolek, C. J., Squire, L. R., Kosslyn, S. M., \& Lulenski, M. E. (1994). Form-specific explicit and implicit memory in the right cerebral hemisphere. Neuropsychology, 8, 588-597.

MAYES, A. R., \& GoOding, P. (1989). Enhancement of word completion priming in amnesics by cueing with previously novel associates. Neuropsychologia, 27, 1057-1072.

McKoon, G., \& Ratcliff, R. (1979). Priming in episodic and semantic memory. Journal of Verbal Learning \& Verbal Behavior, 18, 463480.

McKoon, G., \& RatCLIFF, R. (1986). Automatic activation of episodic information in a semantic memory task. Journal of Experimental Psychology: Learning, Memory, \& Cognition, 12, 108-115.

Micco, A., \& Masson, M. E. J. (1991). Implicit memory for new associations: An interactive process approach. Journal of Experimental Psychology: Learning, Memory, \& Cognition, 17, 1105-1123.

MORTON, J. (1979). Facilitation in word recognition: Experiments causing change in the logogen models. In P. A. Kolers, M. E. Wrolstad, \& H. Bouma (Eds.), Processing of visible language (Vol. 1, pp. 259-268). New York: Plenum.

Moscovitch, M., Winocur, G., \& McLachlan, D. (1986). Memory as assessed by recognition and reading time in normal and memoryimpaired people with Alzheimer's disease and other neurological disorders. Journal of Experimental Psychology: General, 115, 331 347.

Musen, G., \& SQuire, L. R. (1993). On the implicit learning of novel associations by amnesic patients and normal subjects. Neuropsychology, 7, 119-135.

NeEly, J. H., \& DurgunoĞLu, A. Y. (1985). Dissociative episodic and semantic priming effects in episodic recognition and lexical decision tasks. Journal of Memory \& Language, 24, 466-489.

OLDFIELD, R. C. (1971). The assessment and analysis of handedness: The Edinburgh Inventory. Neuropsychologia, 9, 97-113.

Paivio, A., Yuille, J. C., \& Madigan, S. A. (1968). Concreteness, imagery, and meaningfulness values for 925 nouns. Journal of Experimental Psychology Monographs, 76 (1, Pt. 2), 1-25.

PALmer, S. E. (1975). Visual perception and world knowledge: Notes on a model of sensory-cognitive interaction. In D. A. Norman \& D. E. Rumelhart (Eds.), Explorations in cognition (pp. 279-307). San Francisco: W. H. Freeman.

Petersen, S. E., \& Fiez, J. A. (1993). The processing of single words studied with positron emission tomography. Annual Review of Neuroscience, 16, 509-530.

RHODEs, G. (1985). Lateralized processes in face recognition. British Journal of Psychology, 76, 249-271.

RoberTSON, L. C., \& LAMB, M. R. (1991). Neuropsychological contributions to theories of part/whole organization. Cognitive Psychology, 23, 299-330.

Rosenthal, R. (1978). Combining results of independent studies. Psychological Bulletin, 85, 185-193.

Rosenthal, R., \& Rosnow, R. L. (1985). Contrast analysis: Focused comparisons in the analysis of variance. New York: Cambridge University Press.

SCHACTER, D. L. (1990). Perceptual representation systems and implicit memory: Toward a resolution of the multiple memory systems debate. In A. Diamond (Ed.), The development and neural bases of higher cognitive functions (Annals of the New York Academy of Sciences, Vol. 608, pp. 543-571). New York: New York Academy of Sciences.

SCHACTER, D. L. (1992). Understanding implicit memory: A cognitive neuroscience approach. American Psychologist, 47, 559-569.

Schacter, D. L. (1994). Priming and multiple memory systems: Perceptual mechanisms of implicit memory. In D. L. Schacter \& E. Tulving (Eds.), Memory systems 1994 (pp. 233-268). Cambridge, MA: MIT Press.

Schacter, D. L., Alpert, N., Savage, C., Rauch, S., \& Alpert, M. S. (1996). Conscious recollection and the human hippocampal formation: Evidence from positron emission tomography. Proceedings of the National Academy of Sciences, 93, 321-325.

SCHACTER, D. L., \& ChuRCH, B. (1992). Auditory priming: Implicit and explicit memory for words and voices. Journal of Experimental Psychology: Learning, Memory, \& Cognition, 18, 915-930.

Schacter, D. L., Church, B. A., \& Bolton, E. (1995). Implicit memory in amnesic patients: Impairment of voice-specific priming. Psychological Science, 6, 20-25.

Schacter, D. L., CoOper, L. A., \& Delaney, S. M. (1990). Implicit memory for unfamiliar objects depends on access to structural descriptions. Journal of Experimental Psychology: General, 119, 524.

SCHACTER, D. L., \& GRAF, P. (1986a). Effect of elaborative processing on implicit and explicit memory for new associations. Journal of Experimental Psychology: Learning, Memory, \& Cognition, 12, 432444.

Schacter, D. L., \& Graf, P. (1986b). Preserved learning in amnesic patients: Perspectives from research on direct priming. Journal of Clinical \& Experimental Neuropsychology, 8, 727-743.

SCHACTER, D. L., \& GRAF, P. (1989). Modality specificity of implicit memory for new associations. Journal of Experimental Psychology: Learning, Memory, \& Cognition, 15, 3-12.

SCHACTER, D. L., \& Tulving, E. (Eds.) (1994). Memory systems 1994. Cambridge, MA: MIT Press.

SERGENT, J. (1982). The cerebral balance of power: Confrontation or cooperation? Journal of Experimental Psychology: Human Perception \& Performance, 8, 253-272.

SERGENT, J., \& BINDRA, D. (1981). Differential hemispheric processing of faces: Methodological considerations and reinterpretation. Psychological Bulletin, 89, 541-554.

Sergent, J., Ohta, S., \& MacDonald, B. (1992). Functional neuroanatomy of face and object processing. Brain, 115, 15-36.

Shimamura, A. P., \& Souire, L. R. (1989). Impaired priming of new associations in amnesia. Journal of Experimental Psychology: Learning, Memory, \& Cognition, 15, 721-728.

Smith, M. C., MacLeod, C. M., Bain, J. D., \& Hoppe, R. B. (1989). Lexical decision as an indirect test of memory: Repetition and listwide priming as a function of type of encoding. Journal of Experimental Psychology: Learning, Memory, \& Cognition, 15, 1109-1118.

SQUIRE, L. R. (1987). Memory and brain. New York: Oxford University Press.

Squire, L. R., Ojemann, J. G., Miezin, F. M., Petersen, S. E., Videen, 
T. O., \& RaICHLE, M. E. (1992). Activation of the hippocampus in humans: A functional anatomical study of memory. Proceedings of the National Academy of Sciences, 89, 1837-1841.

SUTHERLAND, N. S. (1968). Outlines of a theory of pattern recognition in animal and man. Proceedings of the Royal Society of London: Series $B, 171,297-317$.

TANAKA, J. W., \& Farah, M. J. (1993). Parts and wholes in face recognition. Quarterly Journal of Experimental Psychology, 46A, 225245.

TARR, M. J. (1995). Rotating objects to recognize them: A case study on the role of viewpoint dependency in the recognition of threedimensional objects. Psychonomic Bulletin \& Review, 2, 55-82.

Tootell, R. B. H., Silverman, M. S., Switkes, E., \& De Valois, R. L. (1982). Deoxyglucose analysis of retinotopic organization in primate striate cortex. Science, 218, 902-904.

Tulving, E., \& SCHacter, D. L. (1990). Priming and human memory systems. Science, 247, 301-305.

Ullman, S., \& BASRI, R. (1991). Recognition by linear combinations of models. IEEE Transactions on Pattern Analysis \& Machine Intelligence, 13, 992-1006.

UNGERLEIDER, L. G., \& MishKin, M. (1982). Two cortical visual systems. In D. J. Ingle, M. A. Goodale, \& R. J. W. Mansfield (Eds.), The analysis of visual behavior (pp. 549-586). Cambridge, MA: MIT Press.

VAN KLEECK, M. H. (1989). Hemispheric differences in global versus local processing of hierarchical visual stimuli by normal subjects: New data and a meta-analysis of previous studies. Neuropsychologia, 27, 1165-1178.

Winston, P. (1975). Learning structural descriptions from examples In P. Winston (Ed.), The psychology of computer vision (pp. 157209). New York: McGraw-Hill.

ZaIDEL, D. W. (1987). Hemispheric asymmetry in long-term semantic relationships. Cognitive Neuropsychology, 4, 321-332.

\section{NOTES}

1. It may be important to note that an AVF subsystem and an SVF subsystem probably store duplicate and nonduplicate information. For example, the information that an enclosed space is connected to a vertical line in the form " $p$ " likely is stored in both subsystems. However, the specific kinds of vertices that are present in the form, the specific shape to the enclosed space, and so on, may be information that is stored only in an SVF subsystem.

2. Hemispheric asymmetries are useful tools for testing hypotheses about the relative independence of neural processing subsystems (Hellige, 1993). Although the behavioral results support the claim that two visual-form subsystems operate at least relatively independently, they do not indicate the way in which these subsystems may be lateralized. We remain agnostic about whether these subsystems are strongly lateralized (e.g., one subsystem operates only in one hemisphere) or weakly lateralized (e.g., each subsystem operates in each hemisphere, with different subsystems operating more effectively in the different hemispheres). Behavioral results alone do not enable us to distinguish between these alternatives. However, we wish to emphasize that we do not claim that information presented directly to one hemisphere is processed only by that hemisphere. Rather, we use interaction effects involving hemisphere of direct presentation (Hellige, 1983) and the reasoning described in the text to test hypotheses about the architecture of visual-form subsystems.

3. Although most of the theories of visual-form recognition cited in the Introduction have been developed to account for object recognition, they can be applied to word and letter recognition as well. Indeed, because human beings have been posed with the problem of recognizing word and letter forms for a relatively short time in evolutionary history, it is unlikely that humans have evolved subsystems devoted to word and letter recognition. Instead, subsystems that evolved to perform object, face, and pattern recognition may be recruited to accomplish word and letter recognition.

4. In all analyses in this article, the percentages calculated for criticalword completion rates were conditionalized, in that only trials in which the word stems were accurately perceived by participants were included in the computations of completion rates. Analyses of conditionalized percentages did not differ qualitatively from analyses of nonconditionalized percentages, largely because participants perceived the word stems accurately in high proportions of the trials (range = $.93-.86$ across experiments reported in this article). Furthermore, valid analyses of response times for critical-word completions were not possible in these experiments, because a large number of cells in the design did not include an observation in which a critical word was produced.

5. Although the interactions among context, case, and hemisphere are the important results from this experiment and Experiment $1 \mathrm{~A}$, we should offer a potential explanation for the unexpected finding of an apparent lack of priming in one condition in this experiment (in the same-context, different-case, RH condition; see Figure 3). Assuming that the priming obtained in different-case conditions reflects processing in conceptual systems to a relatively large degree, the lack of priming in that condition could be due to the characteristic processing of RH conceptual subsystems. Conceptual subsystems in the RH process relatively diffuse and wide-ranging semantic information effectively, whereas conceptual subsystems in the $\mathrm{LH}$ process relatively precise and focused semantic information effectively (Beeman et al., 1994; Brownell, 1988; Burgess \& Simpson, 1988; Chiarello, 1991; Zaidel, 1987). Thus, for priming supported by conceptual subsystems, samecontext priming may be large following LH presentations because information about context may be the kind of precise information processed effectively in LH conceptual subsystems; however, samecontext priming may not be large (or may not be found) following $\mathrm{RH}$ presentations because the diffuse information processed in $\mathrm{RH}$ conceptual subsystems may not include information as precise as context.

(Manuscript received May 18, 1995; revision accepted for publication February 4, 1996.) 